Title page:

\title{
Update on the cellular and molecular aspects of Cystic Fibrosis Transmembrane Conductance Regulator (CFTR) and male fertility
}

Yefimova M. ${ }^{1,2,4}$, Bourmeyster N. ${ }^{2}$, Becq F. ${ }^{2}$, Burel A. ${ }^{3}$, Lavault M-T., Jouve G. ${ }^{4}$, Veau S. ${ }^{4}$, Pimentel C. ${ }^{4}$, Jégou B. ${ }^{5,6}$, Ravel C. ${ }^{4,5,6}$.

1)Sechenov Institute of Evolutionary Physiology and Biochemistry, Russian Academy of Sciences, $44 \mathrm{M}$. Thorez pr, 194223, St-Petersburg, Russia.

2) Université de Poitiers, Laboratoire STIM, 1 rue Georges Bonnet, 86022 Poitiers Cedex, France.

3)Univ Rennes, Plateforme de MRIC TEM cellulaire, BIOSIT, 2 av du Pr Léon Bernard, 35000 Rennes, France. 4)Univ Rennes, CHU de Rennes, Département de Gynécologie Obstétrique et Reproduction Humaine, Hôpital Sud, 16 boulevard de Bulgarie, 35000 Rennes, France.

5)Univ Rennes, IRSET-INSERM UMR1085, 9 av du Pr Léon Bernard, 35000 Rennes, France.

6)Université de Rennes1, 2 av du Pr Léon Bernard, 35000 Rennes, France.

Yefimova M: yefimova3@gmail.com

Bourmeyster N: nicolas.bourmeyster@univ-poitiers.fr

Becq F: frederic.becq@univ-poitiers.fr

Burel A: agnes.burel@univ-rennes1.fr

Lavault M-T : marie-therese.lavault@univ-rennes1.fr

Pimentel C : Celine.PIMENTEL@chu-rennes.fr

Jouve G : Guilhem.JOUVE@ chu-rennes.fr

Veau S: Segolene.VEAU@chu-rennes.fr

Jégou B : bernard.jegou@ rennes.inserm.fr

Corresponding author : celia.ravel@chu-rennes.fr

Service de Biologie de la Reproduction-CECOS

16 Bd de Bulgarie, 35000 Rennes, France

Key words: cystic fibrosis, spermatozoa, Sertoli cell, testis, epididymis, mutation, assisted reproductive technology 


\begin{abstract}
CFTR protein regulates electrolyte and fluid transport in almost all tissues with exocrine function, including male reproductive tract. Mutation of CFTR gene causes cystic fibrosis (CF), which affects the function of several organs, and impairs male fertility. The role of CFTR protein in different compartments of male reproductive tract (testis, epididymis, sperm) as well as an impact of CFTR mutation(s) on male fertility phenotype is discussed in relation with the choice of optimal technique for Assisted Reproductive Techniques (ART) management.
\end{abstract}

\title{
Résumé
}

La protéine CFTR est un canal chlore régulant le transport de fluides et d'électrolytes dans presque tous les tissus ayant une fonction exocrine, y compris les voies génitales masculines. Des mutations du gène codant pour cette protéine sont responsables de la mucoviscidose, maladie génétique la plus fréquente en Europe, et de l'aplasie congénitale des canaux déférents. Le rôle joué par la protéine CFTR dans les différents compartiments de l'appareil génital mâle (testicule, épididyme, gamète) ainsi que l'impact d'une mutation CFTR sur le phénotype de fertilité masculine et sa prise en charge thérapeutique sont discutés dans cette revue. 


\section{Introduction}

The CFTR gene codes for a cAMP-dependent protein kinase-activated chloride channel, which belongs to the family of ATP-binding cassette transporters [1]. CFTR protein regulates electrolyte and fluid transport in almost all tissues with exocrine function, in particular in lung and pancreas. Mutation in CFTR gene leads to cystic fibrosis (CF), the most common autosomal recessive disease in Caucasian populations. Among CFTR mutations, F508del is the most frequent which is responsible for the two third of cases in worldwide [2]. The mutation is a deletion of three nucleotides spanning positions 507 and 508 of the CFTR gene on chromosome 7, which ultimately results in the loss of a single codon for the amino acid phenylalanine. CF affects the function of several organs, in particular the trachea, lung, pancreas and several tissues of the reproductive system [3].

Being expressed in the apical membrane of epithelial cells, CFTR regulates many aspects of epithelial physiology, such as maintaining epithelial surface hydration and regulating luminal $\mathrm{pH}$ [4]. Defects in chloride, bicarbonate and water secretion, leading to increased viscosity of the luminal compartment, were proposed as the primary cause of $\mathrm{CF}$ (cited from [3]). Moreover, recent data suggests the implication of CFTR protein in the regulation of tight junction assembly and differentiation of epithelial cell [3]. CFTR also seems to be involved in the regulation of lipid metabolism. Although the underlying mechanisms are poorly understood [5], current evidence indicates the expression of defective CFTR has profounder effect on fatty acid, cholesterol and sphingolipid metabolism, as well as on the membrane phospholipid composition [6].

In this review the current knowledge on CFTR protein in different compartments of male reproductive system will be discussed in relation with the impact of CFTR mutation on several sperm characteristics, functional activity of germ cells and the choice of optimal ART technique in $\mathrm{CF}$ patients.

\section{CFTR protein is present in male reproductive tract from various species}

CFTR protein is highly expressed in male reproductive tract, being detected in the human fetus at the early developmental stages [7-12].

In the testis of rodents the CFTR RNA messenger has been found in developing germ cells, and CFTR protein in the Sertoli cells [13-15]. 
CFTR protein has been also unveiled in the epithelial cells lining the epididymis, and vas deferens [3]. Interestingly, in the epididymis, CFTR shows the region-specific expression, being the most prominent in the distal regions (corpus and cauda) [9].

CFTR protein was also detected in mouse and human sperm [16].

\section{CFTR impacts male gamete formation and functionality on different levels}

CFTR depletion in mice induces an impaired male fertility phenotype. Male mice exhibit the reduced testicular size, and present the signs of epididymis immaturity such as smaller organ weight, reduction in tubule diameter, increase of epithelial cell height in the initial segment and reduction in the expression of markers of epithelial cell differentiation [3]. The sperm from both CF mice and CF patients exhibits the decrease of motility and capacitation $[17,18]$. This suggests that CFTR protein impacts different steps of functional male gamete formation, which progresses in separate compartments of male reproductive tract such as the testis, epididymis and vas deferens.

Studies on rodents demonstrated that in the epididymis CFTR regulated the secretion of chloride and bicarbonate ions [19], while in the testis CFTR has been shown to maintain water homeostasis through its interaction with aquaporin 9 (AQP9) [20] or through direct diffusion of water. The latter is supported by osmotic gradient generated by ion secretion [21]. Thus, in both testis and epididymis CFTR provides establishment of specific fluid environment for germ cell differentiation and maturation. CF mutation of the CFTR gene leads to abnormal luminal environment associated with blockage or agenesis of the epididymis and vas deferens [3, 19].

Besides, inhibition of CFTR in somatic Sertoli cells from the testis or depletion of extracellular $\mathrm{HCO}_{3}{ }^{-}$is thought to reduce $\mathrm{FSH}$-stimulated, sAC-dependent cAMP production, and phosphorylation of CREB, the key transcription factor in spermatogenesis. Indeed, alteration of CFTR protein leads to a diminution of CREB and protamine 2 levels [22], suggesting a possible impact on sperm nuclear integrity at the post-meiotic stages of spermatogenesis, particularly at the step of histone-protamine exchange, which is essential for sperm head condensation and DNA stabilization.

Otherwise, CFTR has been demonstrated to be involved in regulating of tight junctions in the seminiferous tubules of the testis and in the epididymis. In the seminiferous tubules this seems to engage $\mathrm{NF \kappa B} / \mathrm{COX}-2 / \mathrm{PGE} 2$ pathway, because the downregulation of CFTR is accompanied by activation of NFkB, upregulation of COX-2 and downregulation of 
tight junction proteins. Interestingly, such molecular events were observed in a cryptorchidism mouse model [23]. In the epididymis, CFTR regulates tight junction assembly and epithelial cell differentiation, being expressed in Wolffian ducts before ZO-1 protein. CFTR colocalizes with ZO-1 and modulates the expression of proliferation and differentiation genes that are under the control of the ZO-1-ZONAB pathway. The epididymal tubules of $\mathrm{cftr}^{-/-}$and $\mathrm{cftr}^{\mathrm{F} 508 \mathrm{del} / \mathrm{F5} 08 \mathrm{del}}$ mice have reduced ZO-1 levels, increased ZONAB nuclear expression, and decreased epithelial cell differentiation, as illustrated by the reduced expression of apical AQP9 and V-ATPase [3].

Thus, the defective CREB phosphorylation in CF testis along with the ablation of tight junctions and abnormal specific microenvironment in both the testis and epididymis, are likely among harmful factors that contribute to reduced number of both Sertoli and germ cells [24-25] and germ cell malformations in CF patients [26,27].

CFTR protein in sperm cells is thought to be important for the activation of the $\mathrm{HCO}^{-}$ -dependent soluble adenylyl cyclase (sAC) and downstream cAMP/PKA signaling pathway, involved in both sperm motility and capacitation [16].

CF mutation is associated with lipid profile abnormalities: Possible relationship with sperm parameters.

At the systemic level the prominent feature of CF is the abnormalities in both serum and tissue lipid profiles [5]. This results from the defect in the intestinal handling of nutrients and creates a certain state of essential fatty acid and fat-soluble vitamin deficiency [28]. Multiple studies performed on cellular and animal models of CF as well as on CF-affected individuals and obligate heterozygous have shown alterations in fatty acid composition, particularly in the omega-6 and omega-3 PolyUnsaturated Fatty Acid (PUFA). Decreased levels of linoleic acid (LA; 18:2n-6), docosahexaenoic acid (DHA; 22:6n-3) and normal to increased levels of arachidonic acid (AA; 20:4n-6) have frequently been reported in CF plasma, cells and tissues [28,29].

Sperm cells are unique in many respects including structure and function. Their plasma membrane is different from other cells of the body in lipid composition, because of the extremely high level of PUFA. Apart sperm cells, such high level of PUFA is found in the retina and certain brain areas only. PUFA are known to contribute to membrane fluidity and flexibility [30]. 
In human and bull sperm cells the highest concentrations of PUFA (especially DHA) are found in the head and tail [31]. High levels of DHA are thought to contribute to sperm cell mobility, fusogenicity and special permeability characteristics, required for reaching and fusing with oocyte [30]. This notion is supported by studies from rabbit, boar and human sperm, which demonstrated the positive correlation of DHA levels and sperm mobility [3234]. Besides, classical studies in rodents suffering from essential fatty acid deficiency demonstrate a very severe impairment of the spermatogenic tissues [35].

Though lipid metabolism parameters (such as DHA levels) in the germ cells from CF individuals are currently unknown [36], the decrease of motility and capacitation is common feature of CF mice [18] and CF patients sperm [17]. Of note is that acquiring the ability to move forward and to reach, recognize and bind to the oocyte sperm cells obtain during epididymal transit. In both caput and corpus epididymis sperm membrane undergoes pronounced modifications after the interaction with proteins and lipids secreted from the epididymal epithelium. As result, mature sperm reveals increased membrane fluidity and motility due to the increase of PUFA and decrease of cholesterol levels. As recently demonstrated in infertile Dicer1 KO mice with immotile sperm, both cholesterol and PUFA in the epididymis exert the direct effect on sperm maturation and fertility [34].

It seems likely that fatty acid deficiency is among the factors affecting CF male reproductive tract, while the experimental data are still partial. Thus, in vitro studies in $\mathrm{CF}$ cellular models revealed the disorganization and the decrease of thickness of Sertoli-cell derived membranes, supporting the notion on the profound impact of CFTR on membrane phospholipid composition [29, 37]. Moreover, significant disorganization of acrosome and head plasma membrane spermatozoa (Fig.1) was detected in heterozygous F508del-CFTR individuals (data from our laboratory). This is in good agreement with recent study, which demonstrated severely affected sperm head morphology after shifting from optimal lipid concentrations [38]. Such abnormalities could be due to epididymal dysfunction of both lipid and fluid homeostasis. Therefore, CFTR seems to impact different steps of male gamete formation (Fig.2).

\section{Clinical features}

98\% of men heterozygous for CF present the Congenital Bilateral Absence of the Vas Deferens (CBAVD) - a severe defect making sperm excretion impossible, so that after being formed in the testis, the sperm cells are retained in the CF epididymis. This suggests that the 
males showing an isolated CBAVD might present a rough or purely genital form of that disease [39].

Observation of a CF fetus suggest that CBAVD happened by secondary atresia of the vas deferens which take form normally, then involuted probably because of a permeability defect of their lumen [7]. Indeed, no obstruction was detected in both the epididymis and vas deferens of human $\mathrm{CF}$ fetuses [7,40]. Besides, in pre-pubertal boys with $\mathrm{CF}$, epididymal abnormalities are less common than in adult CF patients [3]. This suggests that the progressive atrophy of these tissues occurs relatively late during development, reaching its maximum in adulthood [3]. Because of the tight association of reproductive and kidney system during embryonal development, revealing of CFTR mutations in CBAVD males with normal kidney suggests that CFTR dysfunction alters the vas deferens after its separation from the kidney system [41].

CBAVD is clinically diagnosed when impalpable vas deferens on scrotal examination are associated to testes of normal or subnormal size. Its diagnosis needs also biological and ultrasound explorations, through the discovery of an azoospermia associated to a lowering of the biochemical seminal markers from an epididymal and vesicular origin. Acidic $\mathrm{pH}$, a sperm volume $<1.5 \mathrm{ml}$ and a very decreased fructose are often observed. However, $\mathrm{CF}$-associated CBAVD must be distinguished from the CBAVD associated with kidney anomalies (unilateral, kidney agenesis, pelvian kidney, etc.) which show no relationship whatsoever with CF [41].

\section{Genetic aspects}

While the most frequent mutation of the CFTR gene is the F508del-CFTR mutation, which causes $60 \%$ of cases of cystic fibrosis, more than two thousand variants are described on the CFTR gene, among them 306 are characterized as CF-causing mutations (CFTR2 database) Nearly $50 \%$ of patients suffering from CBAVD were carrying a frequent and severe heterozygous mutation, the F508del-CFTR, present as genetic polymorphism in 3 to $4 \%$ of the general population [42]. As CF is an autosomal recessive disease (affecting one child out of 2500 to 3000 with a heterozygous frequency of 1/25), men affected by CBAVD are often carrying another anomaly on the second allele, consisting either of another mild mutation or of a particular polymorphism aggravating the effect of the first mutation (Fig. 3a). It may concern another mutation ( $\mathrm{R} 117 \mathrm{H}$ is one of the most frequent), or a particular polymorphism aggravating the effect of the first mutation. This is the case of the $5 \mathrm{~T}$ allele due to a polyT 
polymorphism located in intron 8 of the CFTR gene, whose frequency in CBAVD patients is up to six times higher than in the general population [43].

The particularity of the $5 \mathrm{~T}$ allele is to lead to an abnormal maturation of the ARN messengers with the excision of exon 9 at the same time as that of introns 8 and 9, which results into the synthesis of a truncated protein, therefore inefficient (Fig. 3b). There is a variability in the efficiency of the splicing mechanism, among different individuals and between different organs of the same individual. Within the same patient, there exists variability in the ARN maturation of the CFTR gene according to the tissues, with a less good efficiency in the epididymal epithelium than in that of the respiratory tracts [44]. This may explain why patients carrying this $5 \mathrm{~T}$ allele, associated with a mutation on the other allele, would be only affected by CBAVD without showing obvious pulmonary signs.

\section{Impact on ART management}

CFTR patients need to proceed with ICSI (Intra Cytoplasmic Sperm Injection). The existence of a heterozygous mutation in the patient makes it imperative genetic counseling for the partner. Indeed, it is necessary to also find in the patient the presence of a mutation in the CFTR gene to establish the risk of transmission of a CF to the child. The prognosis for progeny is therefore strongly linked to the genetic status of their partner, whose risk to be heterozygous is of $1 / 25$ in case of absence of CF in the family medical background. When the two members of the couple are carrying a CFTR gene anomaly, a prenatal diagnosis or a preimplantation diagnosis can be proposed. Paradoxically, the situation is more complicated when no CFTR anomaly has been found in the partner, which leaves in that case, a residual risk as the partner may be carrying a rare and potentially serious mutation leading to a possible CF (Fig. 3a).

Two surgical techniques are currently practiced: Microsurgical Epididymal Sperm Aspiration (MESA) and testicular biopsy or TESE (TEsticular Sperm Extraction). In our clinical personal experience in our center in Rennes, TESE seems to be more effective [17] in CBAVD patients. Indeed, the important rearrangements of sperm cells took place in the epididymis. This concerns not only membrane modifications (as described above), but also nuclear ones. Ramos and collaborators [45], observed a sperm DNA fragmentation rate almost twice as low in the testis as in the epididymis (9.3\% vs $17.4 \%$, respectively). Moreover, the spermatozoa, whose DNA is fragmented, release a lot of free radicals (ROS: Reactive Oxygen Species). These ROS may have a detrimental effect, causing partial 
fragmentation of the DNA of mature spermatozoa but also affect membrane integrity. Thus, by privileging TESE, one would recover fewer spermatozoa, which are often immobile comparing to epididymal spermatozoa. In rewards, TESE - recovered spermatozoa seem to be morphologically less distorted, supported by efficient Sertoli cells [46]. However as a result of CFTR mutations, patients with CBAVD had a significantly increased risk of miscarriage and stillbirth and a reduced rate of live birth compared with patients with non-CBAVD [47].

\section{Conclusion}

CFTR provides establishment of adequate environment for germ cell development in the testis and maturation in the epididymis, which is achieved through the maintenance of both fluid and lipid homeostasis. Atresia of Vas deferens in heterozygous CF patients leads to the retaining of sperm cells in epididymal compartment with abnormal composition. This may aggravate a detrimental effect of CF mutation on the integrity of sperm cells. Therefore for ART management, testicular biopsy is recommended over microsurgical epididymal sperm aspiration. 


\section{REFERENCES}

1. Riordan JR, Rommens JM, Kerem B, Alon N, Rozmahel R, Grzelczak Z, et al. Identification of the cystic fibrosis gene: cloning and characterization of complementary DNA. Science 1989;245:1066-1073.

2. Bobadilla JL, Macek Jr M, Fine JP, Farrell PM. Cystic fibrosis: a worldwide analysis of CFTR mutations--correlation with incidence data and application to screening. Human Mutation 2002;19: 575-606.

3. Ruan YC, Wang Y, Da Silva N, Kim B, Diao RY, Hill E, et al. CFTR interacts with ZO-1 to regulate tight junction assembly and epithelial differentiation through the ZONAB pathway. J Cell Sci 2014;127:4396-408.

4. Saint-Criq V, Gray MA. Role of CFTR in epithelial physiology. Cell Mol Life Sci 2017;74:93-115.

5. Worgall TS. Lipid metabolism in cystic fibrosis. Curr Opin Clin Nutr Metab Care 2009;12:105-9.

6. Peretti N, Marcil V, Drouin E, Levy E. Mechanisms of lipid malabsorption in Cystic Fibrosis: the impact of essential fatty acids deficiency. Nutr Metab (Lond). 2005;2:11.

7. Gaillard DA, Carre-Pigeon F, Lallemand A. Normal vas deferens in fetuses with cystic fibrosis. J Urol 1997;158:1549-52.

8. Tizzano EF, Chitayat D, Buchwald M. Cell-specific localization of CFTR mRNA shows developmentally regulated expression in human fetal tissues. Hum Mol Genet 1993;2:21924.

9. Ruz R, Andonian S, Hermo L. Immunolocalization and regulation of cystic fibrosis transmembrane conductance regulator in the adult rat epididymis. J Androl 2004;25:265-73.

10. Hihnala S, Kujala M, Toppari J, Kere J, Holmberg C, Höglund P. Expression of SLC26A3, CFTR and NHE3 in the human male reproductive tract: role in male subfertility caused by congenital chloride diarrhoea. Mol Hum Reprod 2006;12:107-11. 
11. Pietrement C, Da Silva N, Silberstein C, James M, Marsolais M, Van Hoek A, et al. Role of NHERF1, cystic fibrosis transmembrane conductance regulator, and cAMP in the regulation of aquaporin 9. J Biol Chem 2008;283:2986-96.

12. Ruan YC, Shum WW, Belleannée C, Da Silva N, Breton S. ATP secretion in the male reproductive tract: essential role of CFTR J Physiol. 2012;590:4209-22.

13. Trezise AE, Buchwald $M$. In vivo cell-specific expression of the cystic fibrosis transmembrane conductance regulator. Nature 1991;353:434-7.

14. Trezise AE, Linder CC, Grieger D, Thompson EW, Meunier H, Griswold MD, et al. CFTR expression is regulated during both the cycle of the seminiferous epithelium and the oestrous cycle of rodents. Nat Genet 1993;3:157-64.

15. Boockfor FR, Morris RA, DeSimone DC, Hunt DM, Walsh KB. Sertoli cell expression of the cystic fibrosis transmembrane conductance regulator. Am J Physiol 1998;274:C922-30.

16. Xu WM, Shi QX, Chen WY, Zhou CX, Ni Y, Rowlands DK, et al. Cystic fibrosis transmembrane conductance regulator is vital to sperm fertilizing capacity and male fertility. Proc Natl Acad Sci U S A 2007;104:9816-21.

17. Beauvillard D, Perrin A, Drapier H, Ravel C, Fréour T, Férec C, et al. Congenital bilateral absence of vas deferens: From diagnosis to assisted reproductive techniques - the experience of three centers. Gynecol Obstet Fertil 2015;43:367-74.

18. Chan HC. CFTR and male fertility-Impact beyond cystic fibrosis. Spermatogenesis 2013;3:e26228.

19. Gong XD, Leung GP, Cheuk BL, Wong PY. Interference with the formation of the epididymal microenvironment--a new strategy for male contraception? Asian J Androl 2000;2:39-45.

20. Jesus TT, Bernardino RL, Martins AD, Sá R, Sousa M, Alves MG, et al. Aquaporin-9 is expressed in rat Sertoli cells and interacts with the cystic fibrosis transmembrane conductance regulator. IUBMB Life 2014;66:639-44. 
21. Ballard ST, Inglis SK. Liquid secretion properties of airway submucosal glands. J Physiol 2004;556:1-10.

22. Xu WM, Chen J, Chen H, Diao RY, Fok KL, Dong JD, et al. Defective CFTR-dependent CREB activation results in impaired spermatogenesis and azoospermia. PLoS One 2011;6:e19120.

23. Chen J, Fok KL, Chen H, Zhang XH, Xu WM, Chan HC. Cryptorchidism-induced CFTR down-regulation results in disruption of testicular tight junctions through up-regulation of NF-kB/COX-2/PGE2. Hum Reprod 2012;27:2585-97.

24. Stern, R. C. Cystic fibrosis and the reproductive system. In: Cystic Fibrosis edited by P. B. Davis. New York: Marcel Dekker, 1993, p. 381-400. (Lung Biol. Health Dis. Ser., vol. 64)

25. Tomashefski, J. F., Jr. The pathology of cystic fibrosis. In: Cystic Fibrosis, edited by P. Davis. New York: Marcel Dekker, 1993, p. 475-477. (Lung Biol. Health Dis. Ser., vol. 64)

26. Denning CR, Sommers SC, Quigley HJ Jr. Infertility in male patients with cystic fibrosis. Pediatrics 1968;41:7-17.

27. Brugman SM and LM Taussig. The reproductive system. In: Cystic Fibrosis edited by L. M. Taussig, New York: Thieme- Stratton; 1984. p. 323-337.

28. Mailhot G, Ravid Z, Barchi S, Moreau A, Rabasa-Lhore R, Levy E. CFTR knockdown stimulates lipid synthesis and transport in intestinal Caco-2/15 cells. Am J Physiol Gastrointest Liver Physiol 2009;297:G1239-G1249.

29. Mailhot G, Rabasa-Lhoret R, Moreau A, Berthiaume Y, Levy E. CFTR depletion results in changes in fatty acid composition and promotes lipogenesis in intestinal Caco 2/15 cells. PLoS One 2010;5:e10446.

30. Mandal R, Badyakar D, Chakrabarty J. Role of Membrane Lipid Fatty Acids in Sperm Cryopreservation. Advances in Andrology 2014;doi:10.1155/2014/190542.

31. Esmaeili V, Shahverdi AH, Moghadasian MH, Alizadeh AR. Dietary fatty acids affect semen quality: a review. Andrology 2015;3:450-61. 
32. Rooke JA, Shao CC, Speake BK. Effects of feeding tuna oil on the lipid composition of pig spermatozoa and in vitro characteristics of semen. Reproduction 2001;121:315-22.

33. Safarinejad MR. Effect of omega-3 polyunsaturated fatty acid supplementation on semen profile and enzymatic anti-oxidant capacity of seminal plasma in infertile men with idiopathic oligoasthenoteratospermia: a double-blind, placebo-controlled, randomised study. Andrologia 2011;43:38-47.

34. Björkgren I, Gylling H, Turunen H, Huhtaniemi I, Strauss L, Poutanen M, et al. Imbalanced lipid homeostasis in the conditional Dicer1 knockout mouse epididymis causes instability of the sperm membrane. FASEB J 2015;29:433-42.

35. Aaes-Jorgensen E, Holmer G. Essential fatty acid-deficient rats. I. Growth and testes development. Lipids 1969;4:501-6.

36. Kim N, Nakamura H, Masaki H, Kumasawa K, Hirano KI, Kimura T. Effect of lipid metabolism on male fertility. Biochem Biophys Res Commun 2017;485:686-692.

37. Yefimova MG, Béré E, Cantereau-Becq A, Harnois T, Meunier AC, Messaddeq N, et al. Myelinosomes act as natural secretory organelles in Sertoli cells to prevent accumulation of aggregate-prone mutant Huntingtin and CFTR. Hum Mol Genet 2016;25:4170-4185.

38. Schisterman EF, Mumford SL, Chen Z, Browne RW, Boyd Barr D, Kim S, et al. Lipid concentrations and semen quality: the LIFE study. Andrology 2014;2:408-15.

39. Bombieri C, Claustres M, De Boeck K, Derichs N, Dodge J, Girodon E, et al. Recommendations for the classification of diseases as CFTR-related disorders. J Cyst Fibros. 2011;10 Suppl 2:S86-102.

40. Marcorelles P, Gillet D, Friocourt G, Ledé F, Samaison L, Huguen G, et al. Cystic fibrosis transmembrane conductance regulator protein expression in the male excretory duct system during development. Hum Pathol 2012;43:390-7.

41. Schwarzer JU, Schwarz M. Significance of CFTR gene mutations in patients with congenital aplasia of vas deferens with special regard to renal aplasia. Andrologia 2012;44:305-7. 
42. Dumur V, Gervais R, Rigot JM, Lafitte JJ, Manouvrier S, Biserte J, et al. Abnormal distribution of CF delta F508 allele in azoospermic men with congenital aplasia of epididymis and vas deferens. Lancet 1990;336:512.

43. Chillón M, Casals T, Mercier B, Bassas L, Lissens W, Silber S, et al. Mutations in the cystic fibrosis gene in patients with congenital absence of the vas deferens. N Engl J Med 1995;332:1475-80.

44. Rave-Harel N, Kerem E, Nissim-Rafinia M, Madjar I, Goshen R, Augarten A, et al. The molecular basis of partial penetrance of splicing mutations in cystic fibrosis. Am J Hum Genet 1997;60:87-94.

45. Ramos L, Kleingeld P, Meuleman E, van Kooy R, Kremer J, Braat D, et al. Assessment of DNA fragmentation of spermatozoa that were surgically retrieved from men with obstructive azoospermia. Fertil Steril. 2002;77:233-7.

46. Ravel C, Jaillard S. [The Sertoli cell]. Morphologie 2011;95:151-8.

47. Lu S, Cui Y, Li X, Zhang H, Liu J, Kong B, et al. Association of cystic fibrosis transmembrane-conductance regulator gene mutation with negative outcome of intracytoplasmic sperm injection pregnancy in cases of congenital bilateral absence of vas deferens. Fertil Steril 2014;101:1255-60. 


\section{Abbreviations}

ART: Assisted Reproductive Technique

AQP9: Aquaporin 9

CBAVD: Congenital Bilateral Absence of the Vas Deferens

CF: Cystic Fibrosis

CFTR: Cystic Fibrosis Transmembrane Conductance Regulator

CREB: C-AMP Response Element-Binding protein

FSH: Follicle Stimulating Hormone

ICSI: Intra Cytoplasmic Sperm Injection

MESA: Microsurgical Epididymal Sperm Aspiration

PUFA: PolyUnsaturated Fatty Acid

ROS: Reactive Oxygen Species

TESE: TEsticular Sperm Extraction 


\section{Declarations}

Ethics approval and consent to participate: Not applicable

Consent for publication: Not applicable.

Availability of data and material: Not applicable

Competing interests: The authors declare that they have no competing interests.

Contributions: MY and CR wrote the manuscript, MY, AB and MTL realized the TEM analysis, $\mathrm{CP}$, GJ, SV, realized clinical ART and taking care of normal and CFTR patients, NB, FB and BJ critically revised the manuscript. All authors have approved the final manuscript.

Funding: This work was supported by the CHU of Rennes and the Rennes1 University. This work was partly supported by the state assignment of FASO of Russia "The mechanisms of development of neuropsychic, metabolic, and hormonal dysfunctions in the nervous and endocrine diseases and the approaches for their correction" (AAAA-A18-118012290427-7).

Acknowledgements: we thank the Plateforme MRIC TEM of BIOSIT (Rennes) and the Biobank GERMETHEQUE. 
Figure Legends:

Figure 1: Electron micrograph reveals acrosomal membrane defects in spermatozoa of CF patient comparing to normal patient .

Figure 2: Hot points of CFTR mutations on male reproductive tract.

Figure 3: Phenotypic variability in CBAVD patients according the type of CFTR mutation. 
Acrosomal membrane of spermatozoa after its maturation in normal and CF microenvironment
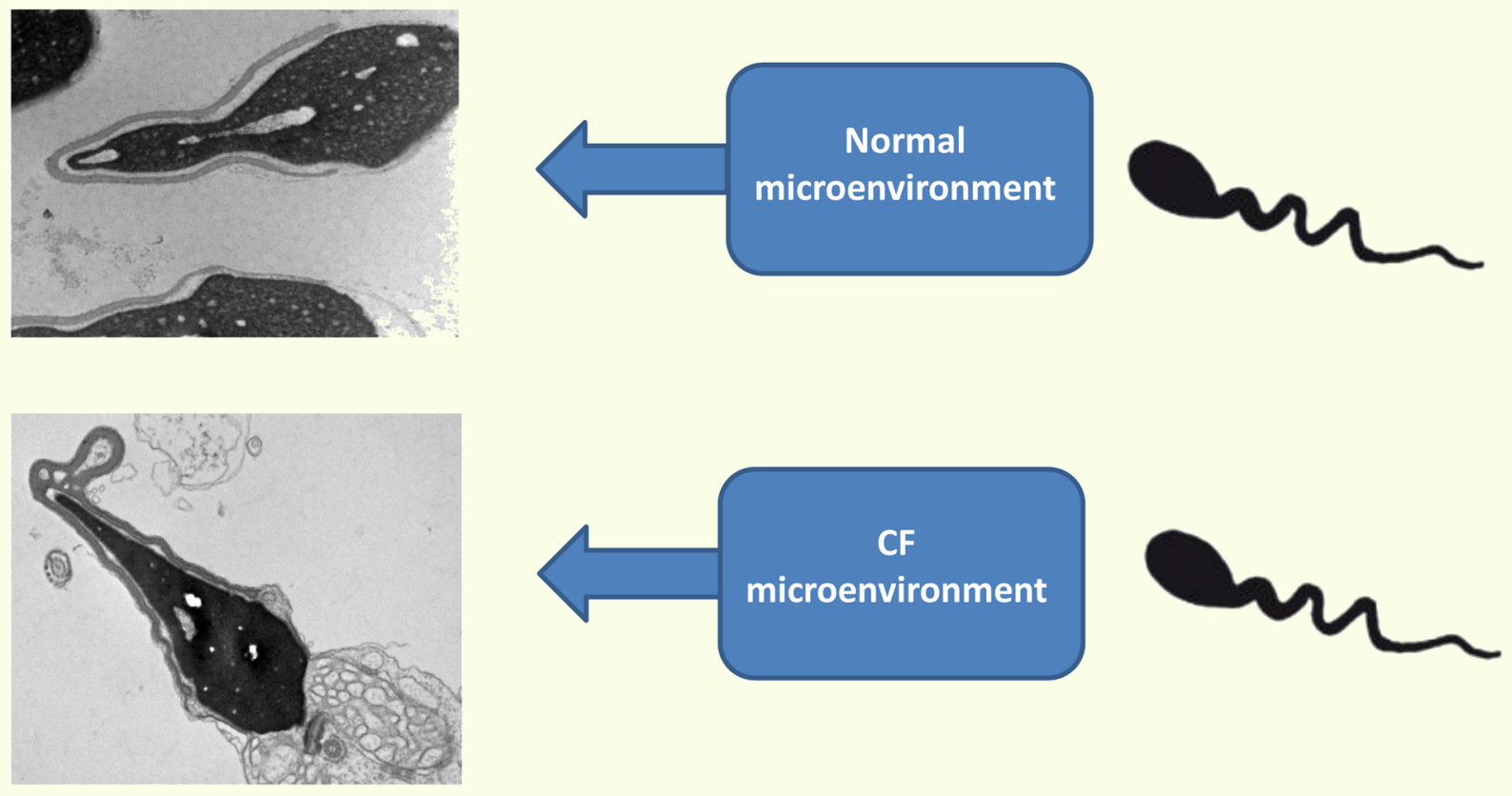


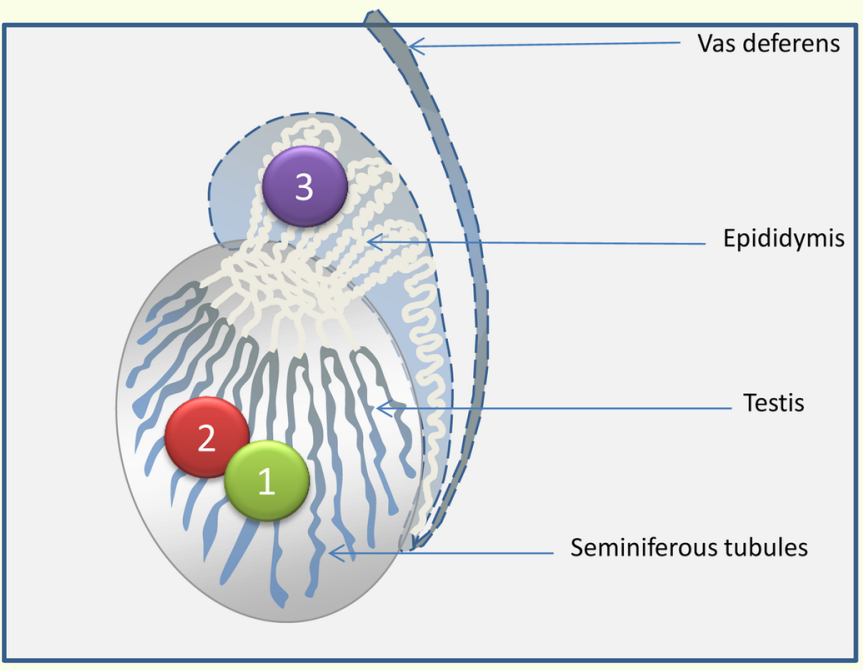

\section{Spermatogenesis}

\section{Spermiogenesis}

\section{Epididymal maturation}

\section{Spermatozoon}

Tight junctions Electrolyte and fluid transport Fatty acid metabolism

Pre-meiotic and meiotic steps

\section{CREB}

Protamine 2

Electrolyte and fluid transport

Fatty acid metabolism
Tight junctions, Electrolyte and fluid transport Fatty acid metabolism

Post-meiotic steps $\searrow \mathrm{HCO}_{3}{ }^{-}$transport

$\searrow C A M P$ production

\section{Spermatozoa production and maturation}




\section{0\% patients CBAVD}

mut $\Delta \mathrm{F} 508$

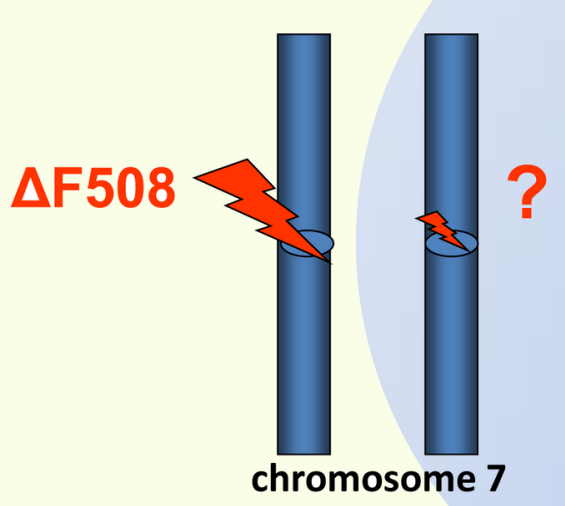

\section{Other CFTR mutations}

(Preferentially associated to CBAVD)

\section{$\mathrm{R} 117 \mathrm{H}$ G542X}

5T Allele

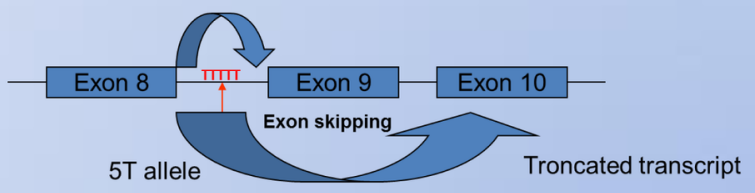

TTTTT: $5 T$ allele TTTTTTT: 7T allele TTTTTTTT: 9T allele

Severe mutation

Mild mutation 